\title{
Effect of polyethylene glycol on in vitro degradability of nitrogen and microbial protein synthesis from tannin-rich browse and herbaceous legumes
}

\author{
G. Getachew, H. P. S. Makkar and K. Becker* \\ Institute for Animal Production in the Tropics and Subtropics, University of Hohenheim (480), \\ D-70593 Stuttgart, Germany
}

(Received 27 November 1998 - Revised 20 October 1999 - Accepted 10 December 1999)

\begin{abstract}
Determination of microbial degradability of $\mathrm{N}$ is important in formulating a sound supplementation strategy for efficient utilisation of basal as well as supplementary diet components. In vitro degradability of N (IVDN) from tannin-containing browses (Acacia cyanophylla, Acacia albida, Acioa barteri and Quercus ilex) and two herbaceous legumes (Desmodium intortum and Desmodium uncinatum) was determined using the in vitro gas-production method coupled with $\mathrm{NH}_{3}-\mathrm{N}$ measurement in the presence and absence of a tannin-binding agent (polyethylene glycol (PEG), molecular mass 6000). Addition of PEG to tannin-containing feeds significantly $(P<0.05)$ increased in vitro gas and short-chain fatty acid (SCFA) production, and IVDN. The use of PEG as a tannin-binding agent increased IVDN from 28 to 59, 32 to 72,19 to 40,32 to 73, 40 to 80 , and 26 to $77 \%$ in A. cyanophylla, A. albida, A. barteri, D. intortum, D. uncinatum and $Q$. ilex respectively. There was significant correlation between total phenolic compounds (total phenol, TP; total tannin, TT) in leguminous forages and percentage increase in IVDN on addition of PEG $\left(P<0.05 ; R^{2} 0.70\right.$ and 0.82 for TP and TT respectively). The difference in IVDN observed in the absence and presence of PEG indicates the amount of protein protected from degradation in the rumen by tannins. When measured after $24 \mathrm{~h}$ incubation, tannin-containing feeds incubated in absence of PEG resulted in higher microbial protein synthesis than in the presence of PEG. Addition of PEG significantly $(P<0.05)$ reduced the efficiency of microbial protein synthesis expressed as $\mu \mathrm{mol}$ purine/mmol SCFA.
\end{abstract}

Polyethylene glycol: Protein degradability: Tannins: Microbial protein synthesis

Herbaceous and tree legumes are rich in $\mathrm{N}$, and these form an integral part of livestock feed in dry seasons in many parts of tropical and subtropical regions where the major feed supply is based on crop residues. Results from in vivo (Campling et al. 1962; Ørskov \& Grubb, 1978), nylon bag (Negi et al. 1988) and in vitro studies (Getachew et al. $1998 c$ ) indicated that the rumen-degradable $\mathrm{N}$ supply from crop residues was not sufficient to meet the maintenance requirement of animals. The nutritive value of crop residues can be enhanced by $\mathrm{N}$ supplementation in the form of leguminous forages. However, the concentration of phenolic compounds (particularly tannin) in multipurpose tree leaves and some herbaceous legumes is generally high; they may bind to protein thus rendering the protein undegradable by rumen microbes. The extent to which tannins in tropical browses and herbaceous legumes bind to proteins and make them undegradable by rumen microbes is not known.

Phenolics are compounds that possess one or more hydroxyl $(\mathrm{OH})$ substituents bonded onto an aromatic ring (Waterman \& Mole, 1994). Tannins are naturally occurring polyphenolic compounds of high molecular mass (500 to $3000 \mathrm{Da}$ ) which form complexes with proteins. Tannins are grouped in two types: (1) the hydrolysable tannins consist of a carbohydrate moiety in which the hydroxyl groups are esterified with gallic acid or ellagic acid, and (2) the condensed tannins consist of oligomers of the flavan-3-ols (the catechins) and related flavanol residues which produce anthocyanidins on acid degradation (Mangan, 1988).

Tannins have both beneficial and adverse effects. Beneficial effects of tannin in ruminants include bloat suppression (Jones et al. 1973) and protection of dietary protein in the rumen and subsequently enhancement of amino acid absorption and utilisation by the ruminant animal (Waghorn et al. 1994). When tannin-containing herbage is masticated, tannin-protein complexes are formed; these are stable over the $\mathrm{pH}$ range 3.5-7.0 but

\footnotetext{
Abbreviations: IVDN, in vitro degradability of nitrogen; NDF, neutral-detergent fibre; NDS, neutral-detergent solution; PEG, polyethylene glycol; SCFA, short-chain fatty acids.

* Corresponding author: Professor K. Becker, fax +49 711459 3702, email kbecker@uni-hohenheim.de
} 
dissociate in the abomasum and anterior duodenum. This protects the protein from microbial hydrolysis and deamination in the rumen and increases the proportion of feed proteins available for digestion and absorption postrumen. Adverse effects of tannins include: (1) lower intake and digestibility; (2) inhibition of digestive enzymes; (3) loss of endogenous proteins; (4) systemic effects as a result of uptake of degraded products of hydrolysable tannins from digestive tract. Condensed tannins do not seem to be degraded by rumen microbes (Makkar et al. $1995 c$ ) and there is no absorption of condensed tannins from the gastrointestinal tract (Terrill et al. 1994). Polyethylene glycol (PEG), with a molecular mass of 4000, is a non-ionic detergent which forms complexes with hydrolysable and condensed tannins over a wide $\mathrm{pH}$ range (2-8.5) (Jones, 1965; Silanikove et al. 1996). PEG of various molecular masses (2000-35 000) have been used to prevent binding between tannins and proteins (Silanikove et al. 1994; Makkar et al. 1995b; Khazaal et al. 1996). PEG can also displace protein from a pre-formed tannin-protein complex (Barry \& Manley, 1986).

Many workers have used chemical assays (Weiss et al. 1992) and nylon-bag techniques (Aufrere et al. 1991; Boila \& Ingalls, 1992, 1995) to assess the protein degradability of conventional feeds. However, these methods are not applicable for tanniferous forages due to the binding of tannins to proteins. Ørskov \& Ryle (1990) mentioned the possible underestimation of DM loss from the nylon-bag due to adherence of microbes and this effect could be much higher for tannin-containing feeds as tannins have high affinity to microbial proteins. Khazaal et al. (1994) compared the in vitro gas and nylon-bag techniques to evaluate nutritive value of feeds and concluded that the nylon-bag technique may not be suitable for evaluating feeds with antinutritive effects. Broderick (1987) developed an in vitro inhibitor technique to measure protein degradability from the appearance of breakdown products such as amino acids and $\mathrm{NH}_{3}$ and the method has been used to study the protein degradability of conventional feeds (Broderick et al. 1992; Neutze et al. 1993). However Broderick \& Albrecht (1997) using feeds containing phenolic compounds reported the binding of these compounds to free amino acids or peptides resulting in a negative rate of protein degradation. The in vitro gas production and $\mathrm{NH}_{3}-\mathrm{N}$ measurement have been used to assess the in vitro degradability of N (IVDN) in protein-rich diets (Raab et al. 1983) and in poor quality roughages (Getachew et al. 1998c).

The objectives of this present study were to evaluate the effect of PEG as a tannin-binding agent on microbial fermentation, efficiency of rumen $\mathrm{NH}_{3}-\mathrm{N}$ uptake and rumen microbial growth when tannin-rich feeds were incubated with buffered rumen fluid in the presence and absence of PEG, and to quantify the extent of tannin-mediated protection of protein from microbial degradation.

\section{Materials and methods}

In vitro gas production, true and apparent digestibility

Tannin-containing plants were selected to study the effect of addition of polyethylene glycol (molecular mass 6000) as a tannin-binding agent since it was found to be the best amongst a number of tannin-binding agents (Makkar et al. $1995 b$ ). Leaves of two browse (Acacia cyanophylla, Acacia albida) two herbaceous legumes (Desmodium intortum and Desmodium uncinatum) were obtained from the International Livestock Research Institute (ILRI, Ethiopia) and Acioa barteri and Quercus ilex were sampled from Bennin (West Africa) and Landesarboretum Hohenheim (Germany) respectively. The plants with known high-tannin content (Makkar et al. 1988, 1995b,d) were taken for this study. Samples were air-dried and ground to pass through $1 \mathrm{~mm}$ screen and used for the IVDN. Feed sample $(0.5 \mathrm{~g})$, starch $(0 \cdot 1 \mathrm{~g})$ and PEG $(1 \mathrm{~g})$ were weighed into glass syringes in their respective order before the buffered rumen fluid was added. Rumen fluid was taken before morning feeding from a rumen-cannulated dairy cow receiving approximately $3 \mathrm{~kg}$ hay/d and straw ad libitum. Rumen fluid was collected into a pre-warmed thermos bottle, homogenised in a laboratory blender, strained using a nylon cloth of $100 \mu \mathrm{m}$ and then filtered through glass wool. All handling was carried out under continuous flushing with $\mathrm{CO}_{2}$. The incubation volume was $40 \mathrm{ml}$. The $\mathrm{N}$ content of the buffered rumen fluid was $7 \cdot 3$ (SD 0.26) $\mathrm{mg}$ ( $n$ 28) in the $40 \mathrm{ml}$ system. The details of procedures and composition of incubation medium are given in Getachew et al. (1998c) and Makkar et al. (1995b). For IVDN determination, two sets of incubations were carried out all in triplicate. First, tannin-containing feeds were incubated with and without starch as described by Raab et al. (1983), and second, the method described earlier was combined with the method outlined by Makkar et al. (1995b); the incubations were as in the first set except that PEG was included. This was repeated in four incubations. Raab et al. (1983) found no significant difference in protein degradability using one level and five levels of starch and therefore one level of starch was used in this present experiment.

After $24 \mathrm{~h}$ incubation, gas production was recorded and for determination of apparent digestibility, the contents of the syringes were transferred into centrifuge tubes and centrifuged at $23000 \mathrm{~g}$ for $15 \mathrm{~min}$ at $4^{\circ} \mathrm{C}$. The supernatant was pipetted into a $50 \mathrm{ml}$ plastic bottle and stored in a freezer until it was analysed for $\mathrm{NH}_{3}-\mathrm{N}$ and SCFA. The syringes were washed twice with a total of $50 \mathrm{ml}$ of $0.2 \%$ $\mathrm{NaCl}$ solution in order to quantitatively transfer the syringe contents into centrifuge tube. The washing solution was emptied each time from the syringes into the same centrifuge tube containing the pellet of the first centrifugation. The tubes were centrifuged again at $23000 \mathrm{~g}$ for $15 \mathrm{~min}$. The residual pellet was frozen and lyophilised in the tubes overnight. The residual moisture, if any, was removed by drying the tubes overnight at $60^{\circ} \mathrm{C}$ and then the tubes were weighed. Apparent digestibility was calculated from the weight of the centrifuge tube containing the pellet minus that of the empty tube and corrected for the pellet weight of the blank incubation. $\mathrm{N}$ in these pellets was determined and termed as apparent undegraded residue-N (APUR-N).

For true digestibility after $24 \mathrm{~h}$ incubation, the syringe contents from parallel sets of incubations were transferred into a $600 \mathrm{ml}$ beaker and the syringes were washed twice with a total of $50 \mathrm{ml}$ neutral-detergent solution (NDS; Van Soest \& Robertson, 1985) and emptied into the beaker. The 
contents were refluxed for $1 \mathrm{~h}$, and then filtered through pre-tared filter crucibles. The crucibles were dried overnight at $100^{\circ} \mathrm{C}$ and weighed (Van Soest \& Robertson, 1985). True degradability was calculated as the weight of substrate incubated minus the weight of the residue after NDS treatment. The residue after NDS treatment (neutral-detergent residue) was used for NDF-N determination. The ratio substrate truly degraded $(\mathrm{mg})$ : gas $(\mathrm{ml})$ volume, termed as partitioning factor (Blümmel et al. 1997b), was calculated using measured gas volume and truly degraded substrate after $24 \mathrm{~h}$ incubation of the feeds.

IVDN was calculated from the linear regressions of $\mathrm{NH}_{3}-\mathrm{N}$ concentration $(y ; \mathrm{mg}) v$. gas production $(x ; \mathrm{ml})$ observed on incubation of feed for $24 \mathrm{~h}$ with and without exogenous energy source (starch), as described in Raab et al. (1983). The intercept at the Y-axis represents the amount of $\mathrm{NH}_{3}-\mathrm{N}$ which is released when no gas was produced. The difference between the $Y$-intercept and $\mathrm{NH}_{3}-\mathrm{N}$ content in $0 \mathrm{~h}$ blank indicated the amount of $\mathrm{NH}_{3}-\mathrm{N}$ liberated from the degradation of protein and other $\mathrm{N}$-containing compounds of the feedstuff incubated. The $\mathrm{NH}_{3}-\mathrm{N}$ in the $24 \mathrm{~h}$ incubated blank was higher than the $0 \mathrm{~h}$ blank values due to microbial lysis that occurred during incubation leading to underestimation of IVDN (Getachew et al. 1998b). Therefore $0 \mathrm{~h}$ blank $\mathrm{NH}_{3}-\mathrm{N}$ values were used in the calculation of IVDN. The IVDN at $24 \mathrm{~h}$ was calculated as a proportion of total $\mathrm{N}$ incubated by the equation:

\section{$\operatorname{IVDN}=$}

$\mathrm{NH}_{3}-\mathrm{N}$ at zero gas production $-\mathrm{NH}_{3}-\mathrm{N}$ in $0 \mathrm{~h}$ blank Total $\mathrm{N}$ of feed incubated

$\mathrm{NH}_{3}-\mathrm{N}$ disappearance with increasing energy (starch) availability was assumed to be due to its incorporation into microbial protein; therefore, the decline in $\mathrm{NH}_{3}-\mathrm{N} / \mathrm{ml}$ gas produced (slope; rate of $\mathrm{NH}_{3}-\mathrm{N}$ uptake) is defined as the efficiency of microbial protein synthesis (Raab et al. 1983).

\section{Microbial nitrogen}

Microbial $\mathrm{N}$ was measured using three different methods: gravimetric (the difference in weight between truly and apparently degraded feed) (Blümmel et al. 1997b), N balance, and purine determination. In the Nitrogen balance method two approaches were used. The first approach was:

$$
\mathrm{MN}=\mathrm{TN}-\left(\mathrm{NDF}-\mathrm{N}+\mathrm{NH}_{3}-\mathrm{N}\right),
$$

where $\mathrm{MN}$ is the microbial $\mathrm{N}, \mathrm{TN}$ is total $\mathrm{N}$ (feed $\mathrm{N}+\mathrm{N}$ in buffered rumen fluid) in the syringe before incubation, and the NDF-N and $\mathrm{NH}_{3}-\mathrm{N}$ are NDF-N and $\mathrm{NH}_{3}-\mathrm{N}$ in the supernatant after $24 \mathrm{~h}$ incubation.

In a closed system, the $\mathrm{N}$ present before incubation (total $\mathrm{N}$ ) will be in the form of microbial mass, NDF-N, amino acids and $\mathrm{NH}_{4}^{+}$after fermentation. Negligible amounts of amino acids and peptides are present in the supernatant during fermentation (Krishnamoorthy et al. 1990) and therefore these can be ignored in calculation of microbial $\mathrm{N}$.

The second approach was:

$$
\mathrm{MN}=\text { APUR-N }- \text { NDF-N, }
$$

where $\mathrm{MN}$ is the microbial $\mathrm{N}$, APUR-N is apparent undegraded residue- $\mathrm{N}$ after incubation. The basis of this approach was similar to that of Blümmel et al. (1997b). The rumen microbial sample was prepared using the method described by Makkar \& Becker (1998) to assess the relationship of purine: $\mathrm{N}$. The efficiency of microbial protein synthesis was defined as $\mu \mathrm{mol}$ purine $/ \mathrm{mmol}$ SCFA.

\section{Chemical analysis}

DM and ash were determined according to the method of the Association of Official Analytical Chemists (1990). NDF and acid-detergent fibre were determined following the method of Van Soest \& Robertson (1985). N in the feeds, apparent undegraded residues and lyophilised rumen microbes was determined by using Kjeldahl procedure. $\mathrm{NH}_{3}-\mathrm{N}$ in the supernatant was also determined using Kjeldahl procedure by distilling $15 \mathrm{ml}$ of the supernatant under alkaline condition (Makkar \& Becker, 1996). Total phenol was determined by Folin-Ciocalteu reagents, total tannins as the difference of phenolics before and after tannin removal with and without the use of insoluble polyvinylpyrrolidone (Makkar et al. 1993), and condensed tannin using the butanol- $\mathrm{HCl}-\mathrm{Fe}$ reagent (Porter et al. 1986). Total phenols and tannins were expressed as tannic acid

Table 1. Chemical composition (\% dry matter) of browse and herbaceous legume species used in the present

\begin{tabular}{|c|c|c|c|c|c|c|c|}
\hline \multirow[b]{2}{*}{ Species } & \multicolumn{7}{|c|}{ Components } \\
\hline & CP & NDF & ADF & Ash & $\mathrm{TP}^{*}$ & $\mathrm{TT}^{*}$ & $\mathrm{CT} \dagger$ \\
\hline Acacia saligna & 14.9 & $40 \cdot 0$ & $46 \cdot 1$ & $10 \cdot 4$ & 13.4 & $10 \cdot 3$ & $10 \cdot 0$ \\
\hline Acacia albida & $9 \cdot 0$ & $35 \cdot 4$ & $43 \cdot 8$ & $9 \cdot 0$ & $12 \cdot 0$ & $11 \cdot 1$ & 7.9 \\
\hline Acioa barteri & 8.6 & $64 \cdot 2$ & 64.6 & $10 \cdot 9$ & 9.7 & 8.5 & 14.8 \\
\hline Desmodium intortum cv greenleaf & $19 \cdot 9$ & $44 \cdot 7$ & 53.2 & $9 \cdot 8$ & 8.5 & $7 \cdot 6$ & $10 \cdot 7$ \\
\hline Desmodium uncinatum cv silverleaf & $19 \cdot 7$ & 47.5 & $55 \cdot 0$ & $10 \cdot 0$ & 8.6 & $7 \cdot 7$ & 8.9 \\
\hline Quercus ilex & $10 \cdot 0$ & $50 \cdot 3$ & $50 \cdot 0$ & $5 \cdot 0$ & 18.5 & $16 \cdot 8$ & $7 \cdot 1$ \\
\hline
\end{tabular}
experiment

$\mathrm{CP}$, crude protein; NDF, neutral-detergent fibre; ADF, acid-detergent fibre; TP, total phenol; TT, total tannin; CT, condensed tannin. * Tannic acid equivalent.

† Leucocyanidin equivalent. 
Table 2. In vitro gas production, ammonia-nitrogen $\left(\mathrm{NH}_{3}-\mathrm{N}\right)$ in $40 \mathrm{ml}$ supernatant $\dagger$, nitrogen in apparent undegraded residue (APUR-N), in vitro dry matter degradability, and partitioning factor (PF) from different browse and herbaceous legumes after $24 \mathrm{~h}$ incubation with and without polyethylene glycol (PEG) and/or starch in buffered rumen fluid (Mean values and standard deviations)

\begin{tabular}{|c|c|c|c|c|c|c|c|c|c|c|c|c|}
\hline \multirow[b]{3}{*}{ Feeds } & \multirow{2}{*}{\multicolumn{2}{|c|}{$24 \mathrm{~h}$ gas $(\mathrm{ml})$}} & \multirow{2}{*}{\multicolumn{2}{|c|}{ APUR-N (mg) }} & \multirow{2}{*}{\multicolumn{2}{|c|}{$\mathrm{NH}_{3}-\mathrm{N}(\mathrm{mg})$}} & \multicolumn{4}{|c|}{ Dry matter degradability (\%) } & \multirow{2}{*}{\multicolumn{2}{|c|}{$\mathrm{PF}(\mathrm{mg} / \mathrm{ml}$ gas) }} \\
\hline & & & & & & & \multicolumn{2}{|c|}{ Apparent } & \multicolumn{2}{|c|}{ True } & & \\
\hline & Mean & SD & Mean & SD & Mean & SD & Mean & SD & Mean & SD & Mean & SD \\
\hline Acacia cyanophylla & 34.6 & 1.34 & $12 \cdot 0$ & 0.23 & 6.9 & 0.20 & $21 \cdot 7$ & $1 \cdot 14$ & $68 \cdot 2$ & 0.49 & $9 \cdot 2$ & 0.07 \\
\hline Acacia + PEG & $66 \cdot 1$ & 1.72 & $8 \cdot 1$ & 0.12 & 10.5 & 0.98 & 23.0 & 2.27 & 59.5 & 1.33 & 4.2 & 0.09 \\
\hline Acacia + starch & $72 \cdot 1$ & 2.51 & 14.9 & 0.38 & 4.4 & 0.38 & 29.7 & 0.48 & 73.1 & 2.28 & $5 \cdot 6$ & 0.17 \\
\hline Acacia + PEG + starch & 105.6 & 3.37 & 9.5 & 0.26 & 8.9 & 0.94 & $32 \cdot 3$ & 1.13 & 63.9 & 0.88 & 3.4 & 0.04 \\
\hline \multicolumn{13}{|l|}{ ANOVA } \\
\hline PEG & $\star * * *$ & & $* * * *$ & & $* * * *$ & & * & & $* * * *$ & & $\star * * * *$ & \\
\hline Starch & $* \star \star \star *$ & & $* \star \star *$ & & **** & & **** & & $* \star *$ & & $\star \star * * *$ & \\
\hline PEG $\times$ Starch & NS & & $* * * *$ & & * & & NS & & NS & & $* * * *$ & \\
\hline Acacia albida & $54 \cdot 2$ & 0.77 & 18.5 & 0.36 & $8 \cdot 6$ & 0.59 & $32 \cdot 4$ & 1.63 & $75 \cdot 2$ & $2 \cdot 40$ & 6.5 & 0.21 \\
\hline Acacia + PEG & 71.1 & 1.59 & $12 \cdot 3$ & 0.22 & 14.9 & $1 \cdot 10$ & 35.9 & 0.70 & $74 . \overline{4}$ & 3.55 & 4.9 & 0.23 \\
\hline Acacia + starch & 92.5 & 3.15 & $21 \cdot 4$ & 0.31 & $5 \cdot 7$ & 0.58 & 38.8 & 1.46 & 79.5 & 0.83 & 4.8 & 0.05 \\
\hline Acacia + PEG + starch & $109 \cdot 8$ & $2 \cdot 37$ & $15 \cdot 1$ & 0.26 & 11.9 & 0.87 & $42 \cdot 1$ & 1.23 & $77 \cdot 2$ & 1.66 & 3.9 & 0.09 \\
\hline \multicolumn{13}{|l|}{ ANOVA } \\
\hline PEG & $* * * *$ & & $* * \star *$ & & $* * * *$ & & $* * *$ & & NS & & $\star * * * *$ & \\
\hline Starch & $* * * *$ & & $* * * *$ & & $* * * *$ & & $* * * *$ & & * & & $* * * *$ & \\
\hline PEG $\times$ Starch & NS & & NS & & NS & & NS & & NS & & * & \\
\hline Acioa barteri & $12 \cdot 7$ & $0 \cdot 16$ & 8.4 & 0.47 & $7 \cdot 3$ & 0.22 & $6 \cdot 0$ & $2 \cdot 27$ & $45 \cdot 0$ & 1.45 & $16 \cdot 1$ & 0.53 \\
\hline Acioa + PEG & $27 \cdot 1$ & 0.91 & 6.9 & 0.46 & $8 \cdot 1$ & 0.64 & $-6 \cdot 4$ & 2.00 & 33.5 & 2.64 & $5 \cdot 6$ & 0.44 \\
\hline Acioa + starch & 51.8 & 1.56 & 9.9 & 0.50 & $5 \cdot 1$ & 0.51 & $17 \cdot 1$ & 0.63 & 52.9 & 0.13 & $5 \cdot 6$ & 0.02 \\
\hline Acioa + PEG + starch & 68.9 & 0.87 & 8.6 & 0.47 & $6 \cdot 1$ & 0.56 & $7 \cdot 0$ & 0.85 & $42 \cdot 5$ & 1.44 & $3 \cdot 4$ & 0.11 \\
\hline \multicolumn{13}{|l|}{ ANOVA } \\
\hline PEG & $* * * *$ & & $* * * *$ & & $* * * *$ & & $* \star * *$ & & $\star \star \star \star *$ & & $* \star \star * *$ & \\
\hline Starch & $* \star \star \star *$ & & $* * \star *$ & & $* * \star *$ & & **** & & $* * * *$ & & $* * * *$ & \\
\hline PEG $\times$ Starch & * & & NS & & NS & & NS & & NS & & $* * * *$ & \\
\hline Desmodium introtum & $70 \cdot 3$ & 0.59 & $14 \cdot 3$ & 0.39 & 8.6 & $0 \cdot 12$ & $34 \cdot 8$ & $3 \cdot 19$ & $70 \cdot 9$ & $2 \cdot 38$ & 4.7 & 0.16 \\
\hline Desmodium + PEG & 84.3 & 1.99 & 9.3 & 0.18 & 13.5 & $0 \cdot 14$ & $32 \cdot 9$ & 0.42 & 68.9 & 2.73 & $3 \cdot 8$ & 0.15 \\
\hline Desmodium + starch & 111.5 & 1.57 & $16 \cdot 1$ & 0.43 & $6 \cdot 7$ & 0.45 & 39.5 & 1.77 & $75 \cdot 7$ & $2 \cdot 86$ & $3 \cdot 8$ & 0.14 \\
\hline Desmodium + PEG + starch & 125.5 & $2 \cdot 24$ & $10 \cdot 9$ & 0.86 & 11.4 & 0.43 & $40 \cdot 6$ & 3.37 & $71 \cdot 2$ & 1.25 & $3 \cdot 2$ & 0.05 \\
\hline \multicolumn{13}{|l|}{ ANOVA } \\
\hline PEG & $* * * *$ & & $* * * *$ & & $* * * *$ & & NS & & * & & $\star * * *$ & \\
\hline Starch & $* * \star *$ & & $* * \star *$ & & **** & & $* * *$ & & * & & $* * * *$ & \\
\hline PEG $\times$ Starch & NS & & NS & & NS & & NS & & NS & & NS & \\
\hline Desmodium uncinatum & $59 \cdot 4$ & $2 \cdot 05$ & 14.6 & 1.06 & $8 \cdot 3$ & 0.24 & $30 \cdot 1$ & 0.72 & $70 \cdot 8$ & 1.02 & $5 \cdot 6$ & 0.08 \\
\hline Desmodium + PEG & $80 \cdot 2$ & 0.68 & 8.5 & 0.13 & 13.9 & 0.23 & $30 \cdot 8$ & 0.60 & 71.2 & 5.06 & 4.2 & 0.30 \\
\hline Desmodium + starch & $86 . \overline{5}$ & 3.59 & $15 \cdot 8$ & 0.61 & $6 \cdot 2$ & 0.25 & 38.6 & 0.53 & $75 \cdot 5$ & 1.34 & $4 . \overline{9}$ & 0.09 \\
\hline Desmodium + PEG + starch & $120 \cdot 8$ & 1.69 & $10 \cdot 6$ & 0.34 & 11.3 & 0.37 & 37.4 & 0.48 & $67 \cdot 7$ & $5 \cdot 36$ & $3 \cdot 1$ & 0.25 \\
\hline \multicolumn{13}{|l|}{ ANOVA } \\
\hline PEG & 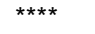 & & 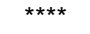 & & **** & & NS & & NS & & $\star * * * *$ & \\
\hline Starch & $* * * *$ & & $* * * *$ & & $* * * *$ & & $\star \star \star * *$ & & NS & & $\star \star \star \star *$ & \\
\hline PEG $\times$ Starch & $* * * *$ & & * & & * & & * & & NS & & NS & \\
\hline Quercus ilex & $49 \cdot 6$ & 1.63 & 9.9 & 0.22 & $5 \cdot 6$ & 0.08 & $25 \cdot 9$ & 0.54 & 58.6 & $2 \cdot 16$ & $5 \cdot 6$ & 0.20 \\
\hline Quercus + PEG & 65.3 & 0.69 & $7 \cdot 6$ & 0.24 & 7.6 & $0 \cdot 16$ & $25 \cdot 8$ & 0.89 & $59 \cdot 6$ & $2 \cdot 30$ & $4 \cdot 3$ & 0.17 \\
\hline Quercus + starch & 88.4 & 1.42 & 11.6 & 0.30 & $3 \cdot 1$ & 0.09 & 33.7 & 0.88 & $62 \cdot 0$ & 3.50 & 4.0 & 0.22 \\
\hline Quercus + PEG + starch & 103.5 & 1.84 & 9.9 & 0.47 & 4.6 & 0.13 & $32 \cdot 9$ & 0.74 & $67 \cdot 1$ & $1 \cdot 13$ & $3 \cdot 7$ & 0.06 \\
\hline \multicolumn{13}{|l|}{ ANOVA } \\
\hline PEG & $* * \star *$ & & $* \star \star *$ & & $\star * \star *$ & & NS & & NS & & $* \star \star * *$ & \\
\hline Starch & $* * * *$ & & $* * * *$ & & $* * * *$ & & $* * * *$ & & ** & & $\star * * *$ & \\
\hline PEG $\times$ Starch & NS & & * & & **** & & NS & & NS & & * & \\
\hline
\end{tabular}

PF, partitioning factor (substrate truly degraded).

${ }^{*} P<0.05,{ }^{* *} P<0.01,{ }^{* \star *} P<0.001,{ }^{\star \star \star *} P<0.0001$

†After centrifugation of syringe contents (see p. 74).

equivalent and condensed tannins as leucocyanidin equivalent. SCFA in the supernatant were determined using GC (Hewlett Packard, 5880A, Avondale, PA, USA) fitted with a flame-ionisation detector. Purine determination in apparent undegraded residues and rumen microbes was carried out using the HPLC method described by Makkar \& Becker (1999). 
were compared using Duncan's multiple range test. The IVDN and $\mathrm{N}$ uptake in the presence and absence of PEG was compared using Student's $t$ test.

\section{Results}

Chemical composition of the feeds, in vitro gas production, rumen ammonia concentration, and true and apparent degradability

The chemical composition of the feeds used in the experiment is given in Table 1. Acid-detergent fibre values were higher than the NDF values. The contents of total phenols, total tannins and condensed tannins ranged from 8.5 to $18.5 \%, 7.6$ to $16.8 \%$, and 7.1 to $14.8 \%$ respectively. There was a large variation in crude protein content of feeds.

In vitro gas production, apparent undegraded residue- $\mathrm{N}$, $\mathrm{NH}_{3}-\mathrm{N}$ in the supernatant, and apparent and true degradability of feeds are shown in Table 2. Addition of PEG to tannin-containing feeds increased in vitro gas production in all feeds. There was significant interaction $(P<0 \cdot 05)$ for in vitro gas production between PEG and starch for $A$. barteri and $D$. uncinatum. The increases ranged between $20 \%$ for D. intortum to $113 \%$ A. barteri. Addition of readily-soluble carbohydrate (starch) increased true digestibility. The addition of PEG reduced $\mathrm{N}$ in apparent undegraded residues in all feeds. In A. albida, the interaction between PEG and starch was not significant $(P>0.05)$ for all variables except the partitioning factor. $\mathrm{NH}_{3}-\mathrm{N}$ in the supernatant was higher $(P<0.05)$ for samples incubated in presence of PEG as compared to its absence. Inclusion of starch significantly $(P<0.05)$ depressed $\mathrm{NH}_{3}-\mathrm{N}$ in the supernatant. Despite considerable increase in gas production in presence of PEG, the apparent and true degradability were not significantly different in the presence and absence of PEG. The partitioning factor ranged from $3 \cdot 1$ to $16 \cdot 1$.

\section{In vitro degradability of nitrogen}

The IVDN ranges were $19-40 \%$ in tannin-containing feed alone and $40-80 \%$ in tannin-containing feed + PEG (Table 3). Addition of PEG increased the availability of protein to rumen microbes by more than $100 \%$. The extent

Table 3. In vitro degradability of nitrogen (IVDN) after $24 \mathrm{~h}$ incubation in the presence and absence of polyethylene glycol (PEG)

(Mean values and standard deviations)

\begin{tabular}{|c|c|c|c|c|c|}
\hline \multirow[b]{3}{*}{ Species } & \multicolumn{4}{|c|}{ IVDN† } & \multirow[b]{3}{*}{$n$} \\
\hline & \multicolumn{2}{|c|}{-PEG } & \multicolumn{2}{|c|}{$+\mathrm{PEG}$} & \\
\hline & Mean & SD & Mean & SD & \\
\hline Acacia cyanophylla & 0.28 & 0.08 & $0.59^{*}$ & $0 \cdot 17$ & 4 \\
\hline Acacia albida & 0.32 & 0.07 & $0.72^{* \star *}$ & 0.07 & 4 \\
\hline Acioa barteri & 0.19 & 0.05 & 0.40 & 0.17 & 4 \\
\hline Desmodium intortum & 0.32 & 0.08 & $0.73^{\star \star *}$ & 0.09 & 4 \\
\hline Desmodium uncinatum & 0.40 & 0.04 & $0.80^{\star * *}$ & 0.04 & 4 \\
\hline Quercus ilex & 0.26 & 0.08 & $0.77^{\star \star *}$ & 0.05 & 4 \\
\hline
\end{tabular}

Mean values were significantly different from control group (-PEG), ${ }^{*} P<0.05$, ${ }^{* \star \star} P<0.001$ (Student' $t$ test).

$\dagger$ Proportion of feed nitrogen incubated
Table 4. Relationship between increase in in vitro degradability of nitrogen (IVDN) and in vitro gas production in presence of polyethylene glycol (PEG), with contents of phenolic compounds

\begin{tabular}{llllll}
\hline & \multicolumn{2}{c}{$\begin{array}{c}\text { Increase in } \\
\text { IVDN (\%) }\end{array}$} & & \multicolumn{2}{c}{$\begin{array}{c}\text { Increase in } \\
\text { in vitro gas (\%) }\end{array}$} \\
\cline { 2 - 3 } Phenolic compounds & $R^{2}$ & $n$ & & $R^{2}$ & $n$ \\
\hline Total phenols & $0.698^{*}$ & 6 & & 0.040 & 6 \\
Total tannins & $0.817^{*}$ & 6 & & 0.004 & 6 \\
Condensed tannins & 0.268 & 6 & & 0.558 & 6 \\
\hline
\end{tabular}

Mean values were significantly different from control group, ${ }^{*} P<0.05$.

of increase in the microbial degradability of $\mathrm{N}$ on addition of PEG indicates the amount of protein protected by tannins from microbial degradation. There was significant correlation between the content of phenolic compound and percentage increase in IVDN (Table 4). There was no significant correlation $\left(P>0.05 ; R^{2} 0.01\right)$ between the combined effect of phenolic content and in vitro gas production. The relationship between the joint effect of phenolic content and IVDN was weak but significant $\left(P<0.05 ; R^{2} 0.22\right)$. Although the overall $\mathrm{N}$ degradability in the medium was higher in presence of PEG, there was no significant difference $(P>0.05)$ in the rate of $\mathrm{NH}_{3}-\mathrm{N}$ uptake by rumen microbes (Table 5). When individual feed was considered, there was significant difference $(P<0.05)$ in the rate of $\mathrm{NH}_{3}-\mathrm{N}$ uptake in the presence and absence of PEG for $A$. cyanophylla, D. intortum and $Q$. ilex. The rate of $\mathrm{NH}_{3}-\mathrm{N}$ uptake tended to be higher when PEG was absent $(0.0683 v$. $0.0606 \mathrm{mg} \mathrm{NH}_{3}-\mathrm{N}$ uptake/ml gas in absence and presence of PEG respectively; Table 5).

\section{Short-chain fatty acid production}

The net total and individual SCFA production values on incubation of tannin-containing feeds with and without PEG are shown in Table 6. Addition of PEG significantly $(P<0.001)$ increased production of total SCFA (from $38 \%$ in D. intortum and to $540 \%$ in A. barteri). Incubation of tannin-containing feed with PEG tended to decrease the molar proportion of propionate. Addition of PEG also

Table 5. Rate of nitrogen uptake (mg N uptake/ml gas) by rumen microbes on addition of starch when tannin-rich browse and herbaceous legumes were incubated with and without polyethylene glycol (PEG)

(Mean values and standard deviations)

\begin{tabular}{|c|c|c|c|c|}
\hline \multirow[b]{3}{*}{ Feeds } & \multicolumn{4}{|c|}{$\mathrm{N}$ uptake (mg/ml gas) } \\
\hline & \multicolumn{2}{|c|}{$-P E G$} & \multicolumn{2}{|c|}{$+\mathrm{PEG}$} \\
\hline & Mean & SD & Mean & SD \\
\hline Acacia cyanophylla & 0.0878 & 0.0258 & $0.0462^{*}$ & 0.0159 \\
\hline Acacia albida & 0.0762 & 0.0159 & 0.0759 & 0.0086 \\
\hline Acioa barteri & 0.0543 & 0.0103 & 0.0459 & 0.0035 \\
\hline Desmodium intortum & 0.0476 & 0.0142 & 0.0540 & 0.0139 \\
\hline Desmodium uncinatum & 0.0781 & 0.0082 & $0.0621^{*}$ & 0.0072 \\
\hline Quercus ilex & 0.0658 & 0.0070 & $0.0794 *$ & 0.0048 \\
\hline
\end{tabular}

Mean values were significantly different from control group (-PEG), * $P<0.05$ (Student's $t$ test). 
Table 6. Net total and individual short-chain fatty acid (SCFA) production ( $\mu \mathrm{mol} / 40 \mathrm{ml}$ incubation medium) on incubation ( $24 \mathrm{~h})$ of browse and herbaceous legumes with and without polyethylene glycol (PEG) and/or starch

(Mean values and standard deviations)

\begin{tabular}{|c|c|c|c|c|c|c|c|c|c|c|c|c|c|c|}
\hline \multirow[b]{2}{*}{ Feeds } & \multicolumn{2}{|c|}{ Total SCFA } & \multicolumn{2}{|c|}{$\mathrm{C} 2$} & \multicolumn{2}{|c|}{ C3 } & \multicolumn{2}{|c|}{$\mathrm{C} 4$} & \multicolumn{2}{|c|}{$\mathrm{C} 4 \mathrm{i}$} & \multicolumn{2}{|c|}{ C5i } & \multicolumn{2}{|c|}{ C5 } \\
\hline & Mean & SD & Mean & SD & Mean & SD & Mean & SD & Mean & SD & Mean & SD & Mean & SD \\
\hline Acacia cyanophylla & 856 & 25.4 & 609 & 20.0 & 284 & 6.1 & -30.7 & 4.0 & -3.7 & 0.46 & -10.9 & 0.69 & 8.0 & 0.92 \\
\hline Acacia + PEG & 1610 & 128.7 & 1089 & 91.7 & 439 & 30.7 & 21.3 & 4.0 & 15.5 & 0.46 & 24.9 & 2.01 & 20.5 & 1.06 \\
\hline Acacia + starch & 1374 & 12.9 & 883 & 23.1 & 503 & 20.1 & -4.7 & 2.8 & -3.9 & 1.29 & -11.2 & 1.67 & 7.3 & 1.83 \\
\hline Acacia + starch + PEG & 2135 & 127.0 & 1369 & 84.9 & 551 & 31.1 & 145.3 & 5.7 & 19.4 & 0.85 & 27.9 & 2.83 & 21.7 & 1.70 \\
\hline \multicolumn{15}{|l|}{ ANOVA } \\
\hline PEG & $* * * *$ & & **** & & $* * * *$ & & $* * * *$ & & & & & & & \\
\hline Starch & $\star \star \star \star *$ & & **** & & **** & & $\star * * * *$ & & & & & & & \\
\hline PEG $\times$ Starch & NS & & NS & & * & & $* * * *$ & & & & & & & \\
\hline Acacia albida & 1103 & 28.6 & 849 & 28.3 & 237 & 0.0 & 9.3 & 0.0 & 1.4 & 0.28 & -1.3 & 0.0 & 7.3 & 0.00 \\
\hline Acacia + PEG & 1648 & 43.0 & 1183 & 30.6 & 328 & 10.1 & 46.6 & 2.3 & 22.5 & 0.46 & 40.5 & 2.31 & 28.0 & 0.61 \\
\hline Acacia + starch & 1676 & 31.2 & 1169 & 20.0 & 393 & 13.9 & 105.3 & 4.0 & 2.1 & 0.23 & -3.2 & 1.22 & 9.1 & 0.23 \\
\hline Acacia + starch + PEG & 2410 & 24.8 & 1643 & 23.1 & 489 & 6.9 & 184.0 & 6.1 & 25.3 & 0.23 & 41.9 & 0.00 & 27.1 & 0.23 \\
\hline \multicolumn{15}{|l|}{ ANOVA } \\
\hline PEG & 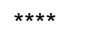 & & **** & & $\star \star \star \star *$ & & $* * * *$ & & & & & & & \\
\hline Starch & $* * * *$ & & $* * * *$ & & $\star * * *$ & & $* * * *$ & & & & & & & \\
\hline PEG $\times$ Starch & * & & * & & NS & & $* * * *$ & & & & & & & \\
\hline Acioa barteri & 62 & 5.7 & 87 & 2.8 & 15 & 2.8 & -30.7 & 0.0 & -2.2 & 0.28 & -4.5 & 1.13 & -3.7 & 0.85 \\
\hline Acioa + PEG & 395 & 45.2 & 316 & 30.6 & 84 & 8.3 & -12.0 & 4.6 & 2.9 & 0.61 & 5.7 & 1.22 & -1.7 & 0.46 \\
\hline Acioa + starch & 720 & 34.4 & 429 & 34.6 & 291 & 8.3 & -2.7 & 0.0 & -1.5 & 0.83 & -2.9 & 1.20 & -1.7 & 0.46 \\
\hline Acioa + starch + PEG & 1224 & 59.6 & 803 & 46.2 & 265 & 4.0 & 136.0 & 10.1 & 5.4 & 3.11 & 8.1 & 3.68 & 1.1 & 0.85 \\
\hline \multicolumn{15}{|l|}{ ANOVA } \\
\hline PEG & $\star \star * * *$ & & **** & & * & & $* \star \star \star *$ & & & & & & & \\
\hline Starch & $* * * *$ & & **** & & **** & & $* * \star *$ & & & & & & & \\
\hline $\mathrm{PEG} \times$ Starch & * & & * & & **** & & $\star * * * *$ & & & & & & & \\
\hline Desmodium intortum & 1646 & 2.5 & 1181 & 0.0 & 342 & 2.8 & 76.0 & 0.0 & 10.6 & 0.28 & 14.2 & 0.28 & 21.8 & 0.28 \\
\hline Desmodium + PEG & 2268 & 18.9 & 1588 & 11.5 & 442 & 6.1 & 126.7 & 2.3 & 28.9 & 0.61 & 44.0 & 0.00 & 38.0 & 0.00 \\
\hline Desmodium + starch & 2456 & 42.0 & 1635 & 23.1 & 552 & 8.0 & 205.3 & 9.2 & 15.1 & 0.83 & 18.9 & 1.40 & 29.9 & 0.61 \\
\hline Desmodium + starch + PEG & 2815 & 112.1 & 1888 & 75.7 & 576 & 17.4 & 236.0 & 14.4 & 31.5 & 0.92 & 44.0 & 4.00 & 39.3 & 2.31 \\
\hline \multicolumn{15}{|l|}{ ANOVA } \\
\hline PEG & $\star * * * *$ & & $* * * *$ & & $* * * *$ & & $* * *$ & & & & & & & \\
\hline Starch & $* * * *$ & & $* * * *$ & & **** & & $* * * *$ & & & & & & & \\
\hline $\mathrm{PEG} \times$ Starch & * & & * & & $* * *$ & & NS & & & & & & & \\
\hline Desmodium uncinatum & 1413 & 29.6 & 1008 & 23.1 & 305 & 6.1 & 68.0 & 0.0 & 7.7 & 0.23 & 6.3 & 1.29 & 17.7 & 0.92 \\
\hline Desmodium + PEG & 2054 & 68.5 & 1435 & 46.2 & 399 & 12.9 & 124.0 & 6.9 & 26.3 & 1.01 & 40.7 & 1.15 & 29.6 & 1.20 \\
\hline Desmodium + starch & 2178 & 11.3 & 1421 & 0.0 & 531 & 8.3 & 181.3 & 2.3 & 10.9 & 0.23 & 11.6 & 0.69 & 21.9 & 0.46 \\
\hline Desmodium + starch + PEG & 2869 & 163.0 & 1915 & 100.7 & 596 & 36.7 & 248.0 & 14.4 & 31.5 & 2.27 & 44.7 & 6.43 & 34.7 & 2.95 \\
\hline \multicolumn{15}{|l|}{ ANOVA } \\
\hline PEG & $\star \star \star * *$ & & **** & & $\star \star \star * *$ & & 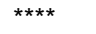 & & & & & & & \\
\hline Starch & $\star \star \star * *$ & & **** & & **** & & $* \star \star *$ & & & & & & & \\
\hline PEG $\times$ Starch & NS & & NS & & NS & & NS & & & & & & & \\
\hline Quercus ilex & 1120 & 13.1 & 835 & 11.5 & 221 & 2.3 & 56.0 & 0.0 & 1.6 & 0.0 & 1.3 & 0.61 & 5.6 & 0.00 \\
\hline Quercus + PEG & 1660 & 54.1 & 1215 & 41.6 & 300 & 10.6 & 109.3 & 2.3 & 10.0 & 0.69 & 14.5 & 1.22 & 11.6 & 0.00 \\
\hline Quercus + starch & 1847 & 48.8 & 1221 & 40.0 & 531 & 6.1 & 82.7 & 2.3 & 2.9 & 0.23 & 2.4 & 1.39 & 7.5 & 0.61 \\
\hline Quercus + starch + PEG & 2249 & 42.4 & 1535 & 30.6 & 529 & 8.3 & 146.7 & 4.6 & 10.7 & 0.46 & 14.0 & 1.39 & 13.9 & 0.23 \\
\hline \multicolumn{15}{|l|}{ ANOVA } \\
\hline PEG & $* * * *$ & & **** & & **** & & $* * * *$ & & & & & & & \\
\hline Starch & $* * * *$ & & $* * * *$ & & $* * * *$ & & $* * * *$ & & & & & & & \\
\hline PEG $\times$ Starch & * & & NS & & $* * * *$ & & * & & & & & & & \\
\hline
\end{tabular}

C2, acetate; C3, propionate; C4, butyrate; C4i, isobutyrate; C5i, isovalerate; C5, valerate.

${ }^{*} P<0.05,{ }^{* * *} P<0.001,{ }^{* * * *} P<0.0001$.

increased the concentration of isoacids. In the absence of PEG there was net uptake of isoacids which is the result of protection of proteins from rumen deamination by tannins. Addition of PEG also increased production of butyrate.

\section{Microbial protein synthesis}

The relationship of purine ( $\mu \mathrm{mol}): \mathrm{N}(\mathrm{mg})$ was found to be 1.4 (SD 0.021) ( $n$ 6). Microbial $\mathrm{N}$ measured using the different methods is presented in Table 7 . The gravimetric method was poorly correlated with the $\mathrm{N}$ balance method.
There was strong correlation $\left(R^{2} 0.98\right)$ between microbial protein synthesis measured using the two $\mathrm{N}$ balance methods. Addition of PEG to tannin-containing feeds increased rumen $\mathrm{NH}_{3}-\mathrm{N}$ concentration but reduced microbial protein synthesis. Incubation of starch with tannincontaining feeds significantly increased microbial protein synthesis. Incubation of tannin-containing feed in combination with PEG and starch yielded higher microbial protein synthesis than with PEG alone. The efficiency of microbial protein synthesis was significantly higher $(P<0.05)$ in tannin-containing feed than tannin-containing feed + PEG. 
Table 7. Microbial protein synthesis on incubation of tannin-rich browses and herbaceous legumes ( $24 \mathrm{~h}$ incubation) in the presence and absence of polyethylene glycol (PEG) and/or starch

\begin{tabular}{|c|c|c|c|c|c|c|c|c|c|c|}
\hline \multirow[b]{4}{*}{ Feeds } & \multicolumn{8}{|c|}{ Microbial N measured (mg) } & & \\
\hline & \multicolumn{4}{|c|}{ Nitrogen balance $†$} & \multirow{2}{*}{\multicolumn{2}{|c|}{ Gravimetric $\ddagger$}} & \multirow{2}{*}{\multicolumn{2}{|c|}{ Purines§ }} & \multirow{2}{*}{\multicolumn{2}{|c|}{$\begin{array}{c}\text { EMPS } \\
\text { ( } \mu \mathrm{mol} \text { purines/ } \\
\text { mmol SCFA) }\end{array}$}} \\
\hline & \multicolumn{2}{|c|}{ Method 1} & \multicolumn{2}{|c|}{ Method 2} & & & & & & \\
\hline & Mean & SD & Mean & SD & Mean & SD & Mean & SD & Mean & SD \\
\hline Acacia cyanophylla & $11 \cdot 1$ & 0.12 & $10 \cdot 3$ & 0.19 & $16 \cdot 3$ & 0.71 & 5.6 & $0 \cdot 15$ & $6 \cdot 6$ & 0.03 \\
\hline Acacia + PEG & 8.5 & 0.73 & $6 \cdot 8$ & 0.09 & $12 \cdot 7$ & 0.27 & $4 \cdot 2$ & 0.17 & $2 \cdot 6$ & 0.30 \\
\hline Acacia + starch & 13.9 & $0 \cdot 13$ & $13 \cdot 1$ & 0.33 & $18 \cdot 2$ & $1 \cdot 16$ & 9.4 & 0.31 & $6 \cdot 8$ & 0.26 \\
\hline Acacia + PEG + starch & $10 \cdot 5$ & 0.27 & $8 \cdot 1$ & 0.50 & $13 \cdot 1$ & $0 \cdot 10$ & $6 \cdot 7$ & 0.23 & $3 \cdot 2$ & 0.19 \\
\hline \multicolumn{11}{|l|}{ ANOVA } \\
\hline PEG & $\star \star \star \star *$ & & 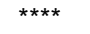 & & & & $\star \star \star * *$ & & 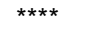 & \\
\hline Starch & $* \star * *$ & & $* * \star *$ & & & & $\star * * *$ & & * & \\
\hline$P E G \times$ Starch & NS & & * & & & & * & & NS & \\
\hline Acacia albida & $16 \cdot 4$ & 0.54 & 14.9 & 0.27 & $15 \cdot 6$ & 1.05 & $7 \cdot 0$ & 0.36 & $6 \cdot 4$ & 0.61 \\
\hline Acacia + PEG & $10 \cdot 7$ & 0.47 & 9.6 & 0.30 & $13 \cdot 9$ & 1.27 & $6 \cdot 0$ & 0.06 & $3 \cdot 7$ & 0.10 \\
\hline Acacia + starch & $18 \cdot 8$ & 0.80 & $17 \cdot 8$ & $0 \cdot 18$ & $17 \cdot 6$ & $0 \cdot 18$ & $11 \cdot 0$ & 0.50 & $6 \cdot 6$ & 0.37 \\
\hline Acacia + PEG + starch & $13 \cdot 7$ & 1.87 & $12 \cdot 6$ & 1.50 & $15 \cdot 1$ & 0.46 & $9 \cdot 7$ & 0.40 & $4 \cdot 0$ & 0.16 \\
\hline \multicolumn{11}{|l|}{ ANOVA } \\
\hline PEG & $* * * *$ & & $* * * *$ & & & & ** & & $* * \star *$ & \\
\hline Starch & * & & $* * * *$ & & & & $\star * \star *$ & & NS & \\
\hline $\mathrm{PEG} \times$ Starch & NS & & NS & & & & NS & & NS & \\
\hline Acioa barteri & 4.0 & 0.04 & $5 \cdot 0$ & 0.07 & 13.9 & 0.40 & 3.0 & 0.27 & $48 \cdot 8$ & 0.01 \\
\hline Acioa + PEG & $2 \cdot 6$ & 0.23 & 3.4 & 0.25 & $15 \cdot 1$ & 0.55 & 3.0 & 0.06 & 7.7 & 0.88 \\
\hline Acioa + starch & $6 \cdot 2$ & 0.21 & $7 \cdot 0$ & 0.27 & $15 \cdot 0$ & 0.23 & 8.9 & 0.32 & $12 \cdot 6$ & 1.08 \\
\hline Acioa + PEG + starch & $4 \cdot 3$ & 0.24 & 4.9 & 0.20 & 14.9 & 0.59 & $5 \cdot 7$ & 0.20 & 4.7 & 0.38 \\
\hline \multicolumn{11}{|l|}{ ANOVA } \\
\hline PEG & $* * * *$ & & $\star \star \star \star *$ & & & & $* \star \star \star *$ & & 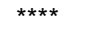 & \\
\hline Starch & $\star \star \star \star *$ & & 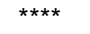 & & & & $\star \star \star * *$ & & $\star \star \star \star *$ & \\
\hline PEG $\times$ Starch & NS & & NS & & & & $* * * *$ & & $* * *$ & \\
\hline Desmodium introtum & $14 \cdot 3$ & 0.08 & $13 \cdot 0$ & 0.30 & $13 \cdot 1$ & 0.94 & 5.9 & 0.36 & 3.5 & 0.09 \\
\hline Desmodium + PEG & 9.6 & 0.08 & 8.7 & 0.12 & $13 \cdot 0$ & 0.84 & $5 \cdot 4$ & $0 \cdot 10$ & $2 \cdot 4$ & 0.02 \\
\hline Desmodium + starch & $15 \cdot 6$ & 0.14 & 14.6 & $0 \cdot 16$ & $15 \cdot 6$ & 1.22 & 8.9 & 0.46 & 3.6 & 0.17 \\
\hline Desmodium + PEG + starch & $11 \cdot 3$ & 0.23 & 9.2 & 0.70 & $13 \cdot 2$ & 1.03 & 7.9 & 0.44 & $2 \cdot 8$ & 0.12 \\
\hline \multicolumn{11}{|l|}{ ANOVA } \\
\hline PEG & 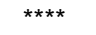 & & 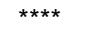 & & & & * & & $* * * *$ & \\
\hline Starch & $* * * *$ & & * & & & & $* * * *$ & & * & \\
\hline $\mathrm{PEG} \times$ Starch & * & & NS & & & & NS & & NS & \\
\hline Desmodium uncinatum & $14 \cdot 0$ & $0 \cdot 10$ & $13 \cdot 8$ & 0.88 & 13.5 & 0.48 & 6.5 & 0.30 & 4.6 & 0.25 \\
\hline Desmodium + PEG & 8.9 & 0.30 & $7 \cdot 7$ & $0 \cdot 10$ & $15 \cdot 1$ & $0 \cdot 13$ & $5 \cdot 2$ & $0 \cdot 12$ & 2.5 & 0.14 \\
\hline Desmodium + starch & $16 \cdot 4$ & 0.17 & $14 \cdot 6$ & 0.46 & $17 \cdot 6$ & 0.68 & 9.8 & 0.29 & 4.5 & 0.16 \\
\hline Desmodium + PEG + starch & $10 \cdot 9$ & 0.36 & 9.4 & 0.28 & $15 \cdot 0$ & 1.72 & 8.2 & $0 \cdot 18$ & $2 \cdot 9$ & 0.22 \\
\hline \multicolumn{11}{|l|}{ ANOVA } \\
\hline PEG & $* * * *$ & & $* * * *$ & & & & $\star * \star \star *$ & & $* * * *$ & \\
\hline Starch & $* \star * *$ & & * & & & & $\star * * *$ & & NS & \\
\hline PEG $\times$ Starch & NS & & NS & & & & NS & & NS & \\
\hline Quercus ilex & $9 \cdot 8$ & $0 \cdot 10$ & $9 \cdot 0$ & $0 \cdot 13$ & $12 \cdot 0$ & 0.65 & $5 \cdot 0$ & $0 \cdot 17$ & 4.5 & 0.19 \\
\hline Quercus + PEG & 7.9 & $0 \cdot 10$ & $6 \cdot 7$ & 0.37 & $12 \cdot 5$ & 0.80 & 4.4 & 0.59 & $2 \cdot 6$ & 0.43 \\
\hline Quercus + starch & $12 \cdot 3$ & $0 \cdot 10$ & $10 \cdot 6$ & 0.38 & $11 \cdot 4$ & 0.31 & $9 \cdot 2$ & 0.06 & $5 \cdot 0$ & 0.16 \\
\hline Quercus + PEG + starch & $10 \cdot 8$ & 0.03 & $9 \cdot 1$ & 0.24 & 14.9 & 0.33 & $9 \cdot 1$ & 0.06 & 4.0 & 0.10 \\
\hline \multicolumn{11}{|l|}{ ANOVA } \\
\hline PEG & **** & & 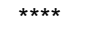 & & & & * & & $\star * * *$ & \\
\hline Starch & $\star \star \star \star *$ & & $* \star * *$ & & & & $\star * * *$ & & $\star \star \star *$ & \\
\hline $\mathrm{PEG} \times$ Starch & * & & * & & & & NS & & * & \\
\hline
\end{tabular}

EMPS, efficiency of microbial protein synthesis.

${ }^{*} P<0.05,{ }^{* *} P<0.01,{ }^{* * *} P<0.001,{ }^{* * * *} P<0.0001$.

† Method 1, total $\mathrm{N}$ in the system - neutral-detergent fibre- $\mathrm{N}+\mathrm{NH}_{3}-\mathrm{N}$ in the supernatant; method 2, apparent undegraded residue- $\mathrm{N}-$ neutral-detergent fibre- $\mathrm{N}$ (see p. 78).

$\ddagger$ Converted to microbial $\mathrm{N}$ assuming an average $\mathrm{N}$ content in microbial dry matter to be $7.7 \%$ (Ørskov \& Ryle, 1990).

$\S \mu \mathrm{mol}$ in apparent residues.

\section{Discussion}

\section{Chemical composition of the feed}

The crude protein content of feeds was within the range reported by Rittner \& Reed (1992). Rittner \& Reed (1992) mentioned high variation in crude protein content of tropical browse species (4.4-38\%). The condensed tannin content was above the level suggested (Barry et al. 1986) to yield positive effects by improving the efficiency of $\mathrm{N}$ digestion. The sugar content of the feeds used in the present study was not analysed. However, Ford (1978) reported $<5 \%$ sugars in Desmodium intortum. Leuaena leucocephala and 
Gliricidia sepium had total sugar contents of 12 and $14 \%$ respectively (Vadiveloo \& Fadel, 1992).

\section{In vitro degradability of nitrogen}

Incubation was carried out in N-rich medium (approximately $182 \mathrm{mg} \mathrm{N} / \mathrm{l}$ ). This value was within the level suggested for optimum rumen fermentation (Ørskov, 1982). Using similar incubation medium, the IVDN values observed from browse and herbaceous legumes in the absence of PEG were lower than those reported for low quality roughages (Getachew et al. 1998c). However, due to their relatively high crude protein content, browses and herbaceous legumes could play a significant role in supplying rumen degradable N. In the presence of PEG, the IVDN values were higher. The difference between IVDN values observed in presence and absence of PEG indicates the amount of protein protected by tannins from degradation in the rumen. Whether this amount of protein protected by tannins from microbial degradation is fully available to animals post-ruminally requires further research. In the current experiment the IVDN was measured after $24 \mathrm{~h}$ incubation. Raab et al. (1983) reported a close relationship between in vivo and in vitro values when incubation was terminated after $17 \mathrm{~h}$. When conventional-protein feed was used, about $80 \%$ of the $24 \mathrm{~h}$ value was degraded in the first $8 \mathrm{~h}$ incubation whereas in protected protein feed only $60 \%$ of the value measured after $24 \mathrm{~h}$ incubation were degraded (Raab et al. 1983). The appropriate incubation time for in vitro degradability studies may depend on the rate of degradability of protein. The presence of phenolic compounds reduces the rate of degradation of feeds (Khazaal et al. 1994; Broderick \& Albrecht, 1997) making the choice of incubation time more complicated. Kaitho et al. (1998) used a range of browse species with different level of phenolic compounds and reported a degradation rate of $-0 \cdot 1-19 \cdot 0 \% / \mathrm{h}$. Broderick \& Albrecht (1997) using the in vitro inhibitor system for tannin-containing feeds reported low rates of degradability of protein. The rate of protein degradability can be affected not only by the amount of phenolic compounds but also by their biological activity (Broderick \& Albrecht, 1997). Condensed tannins from different plant species have been reported to show different physical and chemical properties (Mangan, 1988).

\section{In vitro gas production, apparent and true degradability, and partitioning of nutrients}

Phenolic compounds (particularly tannins) bind to macromolecules, in particular to proteins, forming tannin-protein complexes and creating difficulties in the analysis of fibre using the detergent method (Makkar et al. 1995d). This was also evident from the higher value of acid-detergent fibre as compared to NDF (Table 1). Since tannins are heterogenous in nature their biological activity may depend on the type of tannins and the degree of polymerisation (Makkar et al. 1988). Despite the large increase in gas production, apparent digestibility in presence of PEG was not significantly $(P>0.05)$ different from that observed in absence of PEG mainly due the tannin-PEG complexes which became insoluble in the NDS, distorting the weight of degraded sample (Makkar et al. 1995b,d). For conventional feeds (roughages), the ratio substrate truly degraded: gas volume, termed as the partition factor, ranges from 2.74$4.65 \mathrm{mg} / \mathrm{ml}$ (Blümmel et al. 1997a). A partitioning factor as high as $16 \cdot 1$ has been obtained for A. barteri (Table 2) which is well beyond the theoretical $(2.75-4.41)$ or observed (2.74-4.65) ranges of partitioning factors (Blümmel et al. 1997a). This result also reinforces the observation of Makkar et al. (1997) that due to various artefacts the partitioning factors can not be determined for tannin-rich forages by the approach of residue determination using NDS. This high partitioning factor could be due to: (1) leaching of tannins from the feed during fermentation contributing to the DM loss but without contributing to the gas production; (2) inhibition of cell solubles by tannins; or a combination of (1) and (2) (Makkar et al. 1997; Getachew et al. 1998a). All these results suggest again that the detergent system of fibre analysis should be used with caution for tannin-containing feeds.

Large increases in in vitro gas and SCFA production due to the addition of PEG in this present study confirms that the effect of tannin is on depression of DM degradation. Norton (1994) summarised data on legume supplementation to poor quality roughage and reported that the DM digestibility in legumes ranged from 36-60\% and these values were not significantly different from the values for basal diet. This indicates that the effect of tannins in legumes is not only in reducing $\mathrm{N}$ availability but also to reduce digestibility of other components.

\section{Microbial protein synthesis}

Microbial $\mathrm{N}$ determined by both $\mathrm{N}$ balance methods (see p. 75) take into account the NDF-N. Our previous study (Makkar et al. 1995d) showed that NDF or NDF-N values are distorted to a greater extent if the apparent undegraded residue is subjected to NDS treatment rather than subjecting the syringe contents after fermentation directly to the NDS treatment. In the present study, NDF-N was determined in the NDF residue obtained on subjecting the syringe contents after fermentation directly to the NDS treatment. In addition, had the NDF-N values been affected by artefacts arising from the presence of tannin-microbial protein complexes, the observed partitioning factor should not have been higher than the theoretical range. Therefore, an error, if any, in the NDF-N values is not expected to be large. The higher microbial $\mathrm{N}$ by the gravimetric method than with the $\mathrm{N}$ balance methods can be explained by the presence of tannins and/or tannin-protein complexes in the apparently undegraded residue (Makkar et al. 1995d) leading to an overestimation of microbial mass and hence of microbial $\mathrm{N}$. The conclusions drawn from the microbial $\mathrm{N}$ estimated by these methods are not affected by the factors mentioned earlier since the values obtained under different conditions (with or without PEG and starch) for a tanninrich feed had a similar pattern using any of the three approaches. In addition, the pattern observed for microbial $\mathrm{N}$ was similar to that of purines (Table 7); purines content is an indicator of microbial protein. 


\section{Ammonia-nitrogen concentration}

Addition of PEG increased the $\mathrm{NH}_{3}-\mathrm{N}$ concentration in the supernatant. In tannin-containing feeds, degradability of proteins was markedly depressed by tannins resulting in low $\mathrm{NH}_{3}-\mathrm{N}$ concentration. The increased $\mathrm{NH}_{3}-\mathrm{N}$ in presence of PEG did not increase microbial protein synthesis, probably due to poor synchronisation between $\mathrm{N}$ release and carbohydrate fermentation. An increase in microbial protein synthesis when tannin-containing feeds were incubated with starch indicated that uncoupled fermentation occurred when tannin-containing feed was incubated with PEG leading to accumulation of $\mathrm{NH}_{3}-\mathrm{N}$. A rapid degradation of $\mathrm{N}$ not matched to the availability of energy could lead to accumulation of $\mathrm{NH}_{3}-\mathrm{N}$ in the in vitro system or to a high absorption of $\mathrm{NH}_{3}-\mathrm{N}$ from the rumen in vivo. In vivo, the $\mathrm{NH}_{3}-\mathrm{N}$ not captured in the rumen is absorbed and converted into urea, and the synthesis of urea in the liver requires expenditure of energy, each mole of urea requiring four moles of ATP (Van Soest, 1994). Synchronisation of the rate of degradation of $\mathrm{N}$ and carbohydrate components in the rumen is extremely important for efficient utilisation of rumen $\mathrm{NH}_{3}-\mathrm{N}$ for synthesis of microbial protein. Therefore, it appears that utilisation of browse and other legume species with high tannin levels can be improved by inclusion of tannin-binding agents such as PEG and an additional energy source to trap the $\mathrm{N}$ resulting from the fermentation.

\section{Efficiency of microbial protein synthesis}

Incubation of tannin-containing feeds alone resulted in a higher efficiency of microbial protein synthesis as compared to the values measured in presence of PEG (24 h incubation). Norton \& Ahn (1997) evaluated the effect of PEG infusion to sheep fed on Calliandra calothyrsus and reported higher microbial efficiency in the non-PEG group compared to those infused with PEG. Addition of PEG to starch-containing feeds decreased the molar proportion of propionate and hence the efficiency of microbial protein synthesis compared to that in absence of PEG. Higher propionate production in absence of PEG was also reported by Nunez-Hernandez et al. (1991). The amount of $\mathrm{CH}_{4}$ produced was not measured in the current experiment, but in vitro studies indicated that the amount of $\mathrm{CH}_{4}$ production per unit of degraded substrate was lower as the level of tannin-containing feed in the mixture was increased (Hayler et al. 1998). The use of an anti-methanogenic compound in the diet also increased the propionate:acetate ratio and improved the efficiency of feed utilisation (McCrabb et al. 1997). Lower $\mathrm{CH}_{4}$ production and a higher proportion of propionate are consistent with a higher efficiency of microbial protein synthesis in presence of tannins. In the presence of PEG, not only the amount, but also the composition of microbes was affected (Getachew et al. 1998d). Other explanations for the higher efficiency of microbial yield in the absence of PEG could be that tannins may act as an antilytic agent in the rumen and also lead to better synchronisation of nutrients released during fermentation in presence of tannins. Recently, it has been postulated that tannins at a lower concentration reduce bacteriophages (bacterial viruses) which cause the reduction in the efficiency of feed utilisation in the rumen through the non-specific lysis of bacteria (Klieve et al. 1996). Tannins have also been shown to have anti-protozoal activity (Makkar et al. 1995a) which will also increase the efficiency of microbial protein synthesis in the rumen.

The net microbial mass production would depend on the balance between decreased degradable DM and higher microbial mass production per unit DM digested. The beneficial effect of tannins when forages containing low level of tannins are fed (Barry et al. 1986; Waghorn et al. 1994) could be due to the protection of protein from microbial degradation by tannins; this increases the amount of by-pass protein to the lower gut as well as causing a higher flow of microbial proteins to the intestine as a result of higher efficiency of microbial protein synthesis. To our knowledge, this is the first report which demonstrates unequivocally a lower efficiency of microbial protein synthesis on incubation of tannin-containing feeds with PEG or conversely, higher efficiency of microbial protein synthesis in presence of tannins.

The beneficial effects of tannins include protection of dietary proteins in the rumen and the prevention of bloat. Montossi et al. (1997) reported that addition of PEG to tannin-containing diets reduced live-weight gain. Similar results were reported by Terrill et al. (1992) and Barry et al. (1986). Inclusion of PEG in the diet resulted in reduced non$\mathrm{NH}_{3}-\mathrm{N}$ digested post-rumen, increased $\mathrm{N}$ excreted in urine, and increased rumen $\mathrm{NH}_{3}-\mathrm{N}$ (Barry et al. 1986). These authors also reported an increase in apparent digestibility in the PEG-treated group. Degen et al. (1998) used PEG with Acacia saligna, diets containing Quebracho tannin, and tannic acid, and found that addition of PEG increased DM intake and body-weight gain not only for Acacia and Quebracho (which contain mainly condensed tannins) diets but also for tannic acid diets (hydrolysable tannin). This suggests that the effect of PEG in vivo is not only restricted to condensed tannins but also to the hydrolysable tannins in feeds.

The extent of positive or negative effects of tannins may vary depending on the type and level of tannins in feeds and their biological activity, level of tannin intake, and quality of basal diets. Addition of PEG is advantageous if the tannin content of the feed is high to the extent that it depresses microbial activity and digestibility of feeds drastically. On the other hand, addition of PEG to low-tannin feeds may result in negative effects by reducing the amount of by-pass protein and also by decreasing the efficiency of microbial protein synthesis.

\section{Conclusion}

Browse and herbaceous legumes are rich in $\mathrm{N}$ content, and these form an integral part of livestock feed in the dry season in many parts of tropical regions. The consumption of a feedstuff containing high levels of tannins produces adverse effects on nutritive value of feed and animal performance, and therefore there is a tendency to select forages for low tannin content. Screening of germplasm against tannin content may result in disappearance of the important genes responsible for the agronomic, ecological and nutritional advantages of the plants. Addition of PEG 
to tannin-containing feed increased in vitro gas and SCFA production, and in vitro degradation of $\mathrm{N}$. Therefore, there appears to be a potential to improve the utilisation of tannin-containing feeds without altering the genetic pool of tannin-containing plants with the use of a tannin-binding agent such as PEG. Inclusion of energy sources with the aim of synchronising $\mathrm{N}$ degradability and availability of energy could increase the efficiency of microbial protein synthesis in the presence of PEG. Provision of additional energy sources in PEG- and tannin-containing feed would also increase the efficiency of utilisation of resources and ensure environmentally sound feeding systems. The results obtained in the present study indicate the possibility of improving the utilisation of tannin-containing plants, which have an agronomic advantage over the non tannincontaining plants in their adaptation to biotic and environmental stresses.

\section{Acknowledgement}

G. Getachew is grateful to the DAAD (Deutscher Akademischer Austauschdienst) for the financial assistance during the course of this work.

\section{References}

Association of Official Analytical Chemists (1990) Official Methods of Analysis of the Association of Official Analytical Chemists. Washington, DC: AOAC.

Aufrere J, Gravion D, Demarquilly C, Verite R, Michalet-Doreau B \& Chapoutot P (1991) Predicting in situ degradability of feed proteins in the rumen by two laboratory methods (solubility and enzymatic degradation). Animal Feed Science and Technology 33, 97-116.

Barry TN \& Manley TR (1986) Interrelationships between the concentrations of total condensed tannin, free condensed tannin and lignin in Lotus sp. and their possible consequences in ruminant nutrition. Journal of Food Science and Agriculture 37, 248-254.

Barry TN, Manley TR \& Duncan J (1986) The role of condensed tannins in the nutritional value of Lotus pendiculatus for sheep. 4. Sites of carbohydrate and protein digestion as influenced by dietary reactive tannin concentration. British Journal of Nutrition 55, 123-137.

Blümmel M, Makkar HPS \& Becker K (1997a) In vitro gas production: a technique revisited. Journal of Animal Physiology and Animal Nutrition 77, 24-34.

Blümmel M, Steingass H \& Becker K (1997b) The relationship between in vitro gas production, in vitro microbial biomass yield and ${ }^{15} \mathrm{~N}$ incorporation and its implications for the prediction of voluntary feed intake of roughages. British Journal of Nutrition 77, 911-921.

Boila RJ \& Ingalls RJ (1992) In situ rumen digestion and escape of dry matter, nitrogen and amino acids in canola meal. Canadian Journal of Animal Science 72, 891-901.

Boila RJ \& Ingalls RJ (1995) Prediction of rumen undegradable amino acids that are digested post-ruminally. Canadian Journal of Animal Science 75, 583-592.

Broderick G (1987) Determination of protein degradation rates using a rumen in vitro system containing inhibitors of microbial nitrogen metabolism. British Journal of Nutrition 58, 463-475.

Broderick G, Abrams SM \& Rotz CA (1992) Ruminal in vitro degradability of protein in alfalfa harvested as standing forage or baled hay. Journal of Dairy Science 75, 2440-2446.
Broderick G \& Albrecht KA (1997) Ruminal in vitro degradation of protein in tannin-free and tannin containing forage legume species. Crop Science 37, 1884-1891.

Campling RC, Freer M \& Balch CC (1962) Factors affecting the voluntary intake of food by cows. 3 . The effect of urea on the voluntary intake of oat straw. British Journal of Nutrition 15, 115-124.

Degen AA, Mishorr T, Makkar HPS, Kam M, Benjamin RW, Becker K \& Schwartz HJ (1998) Effect of Acacia saligna with and without administration of polyethlene glycol on dietary intake in desert sheep. Animal Science 67, 491-498.

Ford CW (1978) In vitro digestibility and chemical composition of three tropical pasture legumes, Desmodium intortum cv. Greenleaf, Desmodium tortuosum and Macroptilium atropurpureum cv. Siratro. Australian Journal of Agricultural Research 29, 963-974.

Getachew G, Blümmel M, Makkar HPS \& Becker K (1998a) In vitro gas measuring techniques for assessment of nutritional quality of feeds: a review: Animal Feed Science and Technology 72, 261-281.

Getachew G, Makkar HPS \& Becker K (1998b) In vitro rumen degradability of protein in tannin-rich browses and herbaceous legumes in presence and absence of a tannin-complexing agent, polyethylene glycol (PEG 6000) - an approach for determination of tannin-mediated protection of dietary protein from degradation in the rumen. Proceedings of the Society of Nutrition and Physiology 7, 34.

Getachew G, Makkar HPS \& Becker K (1998c). The in vitro gas coupled with ammonia nitrogen measurement for evaluation of nitrogen degradability in low quality roughages using incubation medium of different buffering capacity. Journal of Food Science and Agriculture 77, 87-95.

Getachew G, Makkar HPS \& Becker K (1998d) Tannin-binding agents to alleviate anti-fermentative effects in the rumen. Proceedings of the 3rd Tannin Conference, pp. 57-58 [GG Gross and RW Hemingway, editors]. Bend, OR, USA.

Hayler R, Steingaß H \& Drochner W (1998) Effects of various feedstuffs rich in tannin content on rumen methanogenesis in vitro using the Hohenheim Gas test. Proceedings of Society of Nutrition and Physiology 7, 35.

Jones DE (1965) Banana tannin and its reaction with polyethylene glycols. Nature 206, 299-300.

Jones WT, Anserson LB \& Ross MD (1973) Bloat in cattle: Detection of protein precipitants (flavolans) in legumes. New Zealand Journal of Agricultural Research 16, 441-446.

Kaitho RJ, Umunna NN, Nsahlai IV, Tamminga S \& Bruchem JV (1998) Nitrogen in browse species: Ruminal degradability measured by mobile nylon bag and in vitro techniques. Journal of Food Science and Agriculture 76, 488-498.

Khazaal KA, Boza J \& Ørskov ER (1994) Assessment of phenolics-related antinutritive effects in Mediterranean browse: a comparison between the use of the in vitro gas production technique with or without polyvinylpolypyrrolidone or nylon bag. Animal Feed Science and Technology 49, 133-149.

Khazaal K, Parissi Z, Tsiouvaras C, Nastis A \& Ørskov ER (1996) Assessment of phenolics-related anti-nutritive levels using the in vitro gas production technique: A comparison between different types of polyvinylpolypyrrolidone or polyethylene glycol. Journal of Food Science and Agriculture 71, 405-414.

Klieve AV, Swain RA \& Nolan JV (1996) Bacteriophages in the rumen; types present, population size and implications for the efficiency of feed utilisation. Proceedings of Australian Society of Animal Production 21, 92-94.

Krishnamoorthy U, Steingass H \& Menke KH (1990) The contribution of ammonia, amino acids and short peptides to estimate of protein degradability in vitro. Journal of Animal Physiology and Animal Nutrition 63, 135-141. 
Makkar HPS \& Becker K (1996) Nutritional value and antinutritional components of whole and ethanol extracted Moringa oleifera leaves. Animal Feed Science and Technology 63, 211-228.

Makkar HPS, Blümmel M \& Becker K (1997) In vitro rumen apparent and true digestibilities of tannin-rich forages. Animal Feed Science and Technology 67, 245-251.

Makkar HPS \& Becker K (1999) Purine quantification in digesta from ruminants by spectrophotometric and HPLC methods. British Journal of Nutrition 81, 107-112.

Makkar HPS, Becker K, Abel H \& Szegletti C (1995a) Degradation of condensed tannins by rumen microbes exposed to Quebracho tannins (QT) in rumen Simulation Technique (RUSITEC) and effects of QT on fermentative processes in the RUSITEC. Journal of Food Science and Agriculture 69, 495-500.

Makkar HPS, Blümmel M \& Becker KB (1995b) Formation of complexes between polyvinyl pyrrolidones or polyethylene glycol and tannins, and their implication in gas production and true digestibility in vitro techniques. British Journal of Nutrition 73, 897-913.

Makkar HPS, Blümmel M \& Becker KB (1995c) In vitro effects of and interactions between tannins and saponins and fate of tannins in the rumen. Journal of Food Science and Agriculture 69, 481-493.

Makkar HPS, Blümmel M, Borowy NK \& Becker K (1993) Gravimetric determination of tannins and their correlation with chemical and protein precipitation methods. Journal of Food Science and Agriculture 61, 161-165.

Makkar HPS, Borowy NK, Becker K \& Degen A (1995d) Some problems in fibre determination of a tannin-rich forage (Acacia saligna leaves) and their implications in in vivo studies. Animal Feed Science and Technology 55, 67-76.

Makkar HPS, Dawra RK \& Singh B (1988) Changes in tannin content, polymerisation and protein precipitation capacity in Oak (Quercus incana) leaves with maturity. Journal of Food Science and Agriculture 44, 301-307.

McCrabb GJ, Berger KT, Manger T, May C \& Hunter RA (1997) Inhibiting methane production in Brahman cattle by dietary supplementation with a novel compound and the effects on growth. Australian Journal of Agricultural Research 48, 323 329.

Mangan JL (1988) Nutritional effects of tannins in animal feeds. Nutrition Research Reviews 1, 209-231.

Montossi F, Liu F, Hodgson J, Morris ST, Barry TN \& Risso DF (1997) Influence of low-level condensed tannins concentrations in temperate forages on sheep performance. Proceedings of the XVIIIth International Grassland Congress, vol. 1, pp. 8.1-8.2. Winnipeg, Manitoba, Saskatoon, Saskatchewan, Canada.

Negi SS, Singh B \& Makkar HPS (1988) An approach to the determination of rumen degradability of nitrogen in lowgrade roughages and partition of nitrogen therein. Journal of Agricultural Science 111, 487-494.

Neutze SA, Smith RL \& Forbes WA (1993) Application of an in vitro method for estimating rumen degradation of feed protein. Animal Feed Science and Technology 40, 251-265.

Norton BW (1994) Tree legumes as dietary supplements for ruminants. In Forage Tree Legumes in Tropical Agriculture, pp. 193-201 [RC Gutterdge and HM Shelton, editors]. Wallingford: $\mathrm{CAB}$ International.
Norton BW \& Ahn JH (1997) A comparison of fresh and dried Calliandra calothyrsus supplements for sheep given a basal diet of barley straw. Journal of Agricultural Science 129, 485-494.

Nunez-Hernandez G, Wallace JD, Holechek JL, Galyean ML \& Cardenas M (1991) Condensed tannins and nutrient utilisation by lambs and goats fed low-quality diets. Journal of Animal Science 69, 1167-1177.

Ørskov ER (1982) Protein Nutrition in Ruminants. London: Academic Press.

Ørskov ER \& Grubb DA (1978) Validation of new systems for protein evaluation in ruminants by testing the effect of urea supplementation on intake and digestibility of straws with or without sodium hydroxide treatment. Journal of Agricultural Science 91, 483-486.

Ørskov ER \& Ryle M (1990) Energy Nutrition in Ruminants. London: Elsevier.

Porter LJ, Hrstich LN \& Chan BG (1986) The conversion of proanthocyanidins and prodelphinidins to cyanidin and delphinidin. Phytochemistry 25, 223-230.

Raab L, Cafantaris B, Jilg T \& Menke KH (1983) Rumen protein degradation and biosynthesis. 1. A new method for determination of protein degradation in the rumen fluid in vitro. British Journal of Nutrition 50, 569-582.

Silanikove N, Nitsan Z \& Perevolotsky A (1994) Effect of a daily supplementation of polyethylene glycol on intake and digestion of tannin-containing leaves (Ceratonia siliqua) by sheep. Journal of Agricultural and Food Chemistry 42, 2844-2847.

Silanikove N, Shinder D, Gilboa N, Eyal M \& Nitsan Z (1996) Binding of polyethyelene glycol to samples of forage plants as an assay of tannins and their negative effects on ruminal degradation. Journal of Agricultural and Food Chemistry 44, 3230-3234.

Terrill TH, Douglas GB, Foote AG, Purchas RW, Wilson GF \& Barry TN (1992) Effect of condensed tannins upon body growth, wool growth and rumen metabolism in sheep grazing sulla (Hedysarum coronarium) and perennial pasture. Journal of Agricultural Science 119, 265-273.

Terrill TH, Waghorn GC, Woolley DJ, McNabb WC \& Barry TN (1994) Assay and digestion of ${ }^{14} \mathrm{C}$-labelled condensed tannins in the gastrointestinal tract of sheep. British Journal of Nutrition 72, 467-477.

Vadiveloo J \& Fadel JG (1992) Compositional analyses and rumen degradability of selected tropical feeds. Animal Feed Science and Technology 37, 265-279.

Van Soest PJ (1994) Nutritional Ecology of the Ruminant, 2nd ed. Ithaca, NY: Cornell University Press.

Van Soest PJ \& Robertson JB (1985) A Laboratory Manual for Animal Science 612. Ithaca, NY: Cornell University Press.

Waghorn GC, Shelton ID, McNabb WC \& McCutcheon SN (1994) Effect of condensed tannins in Lotus pedunculatus on its nutritive value for sheep. 2. Nitrogenous aspects. Journal of Agricultural Science 123, 109-119.

Waterman PG \& Mole S (1994) Analysis of Phenolic Plant Metabolites. London: Blackwell Scientific Publications.

Weiss BP, Conrad HR \& Pierre NRS (1992) A theoreticallybased model for predicting total digestible nutrient values of forages and concentrates. Animal Feed Science and Technology 39, 95-110. 